\title{
Information-Categorical Formalization of Processes and Objects of Oil and Gas Object Domain
}

\author{
Mykola Yatsyshyn, Vladimir Yurchushun, Yaroslav Storog, Mykola Pasyeka \\ Department of Software of Automated Systems, Institute of Information Technology, Ivano-Frankivsk National Technical University of Oil \\ and Gas, Ivano-Frankivsk, Ukraine
}

Email address:

leuro@list.ru (M. Pasyeka)

\section{To cite this article:}

Mykola Yatsyshyn, Vladimir Yurchushun, Yaroslav Storog, Mykola Pasyeka. Information-Categorical Formalization of Processes and Objects of Oil and Gas Object Domain. International Journal of Oil, Gas and Coal Engineering. Vol. 5, No. 6, 2017, pp. 184-188. doi: $10.11648 /$ j.ogce.20170506.19

Received: February 7, 2017; Accepted: March 1, 2017; Published: January 15, 2018

\begin{abstract}
Abctract: In this research paper there was made a new approach to the oil and gas index area description at the category level and inorganic deposit in a borehole formation prognostication process at the category level. The importance of the decision support problem on the levels of exploration, prospecting and exploitation of oil and gas deposits has revived high and permanent interest in this scope of an inquiry. Theory of category use for the quantity and quality info streams calculation for the weak-structured oil and gas object description. It is efficient to use the existing oil and gas field stripping technologies on the basis of this theory.
\end{abstract}

Keywords: Prognostication Process, Inorganic Deposit, Prognostication Process, Decision Support Problem, Exploitation of Oil and Gas, Weak-Structured Object Description

\section{Topic Actuality}

Exploration, prospecting, development and exploitation of oil and gas deposits are impossible without implementation of information technologies in order to organize the system of gathering, storing and appropriate processing not only quantitative, but also qualitative information for expert's decision support in the process of control of oil deposit life period. This explains the intensity of scientific researches in the particular field, which are caused by the low level of knowledge formalization, and which limit the ability of mathematical models application.

\section{The Aim of the Study}

The importance of the decision support problem on the levels of exploration, prospecting and exploitation of oil and gas deposits has revived high and permanent interest in this scope of an inquiry.

The research direction chosen is topical because of its orientation to rationalization and intensification of oil and gas expert's intellectual activity in the decision-making process on all levels of oil deposit life history, validating and selection of directions and methods of a deposit development $[7,12]$.

In this research the formalization of oil and gas object domain that appeared in the papers [8,9], build upon the idea of categorical specification of data suggested in $[6,13,14]$ is developed.

\section{The Task}

The introduction of categorical interpretation of the object domain on the basis of predicate diagrams

Definition 1: Categorical data specification (Kspecification), according to [6], will be considered to be a tap $(C, M, F)$ where:

1. C - finite category;

2. $M$ - finite aggregate of objects in $C$;

3. F: $C_{0} \rightarrow$ FinSet - functor, where $C_{0}$ is a discrete category, the object set of which is the set of $C$ objects.

Definition 2: The predicate diagram on the set of unary predicates $\Pi$, according to [8], will be considered an object $\eta$ $=\left(B^{(\eta)}, R^{(\eta)}, f_{1}^{(\eta)}, f_{2}^{(\eta)}, n^{(\eta)}\right)$, where every element has its corresponding predicate $\left(n: B^{(\eta)} \cap R^{(\eta)} \rightarrow \Pi\right), B$ - vertex set, $\mathrm{R}$ - arc set, $f_{l}$ and $f_{2}$ - functions, that for every arc determine 
its beginning and its end.

Definition 3: The model of K-specification of data for oil and gas object domain will be considered to be a tap $(M, \psi$, II) where:

1. $M: C \rightarrow$ FinSet is a functor, for which every $\mu \varepsilon M$ is mono arrow;

2. $\Psi: M^{\circ} I \rightarrow F$ - natural mapping, where I: $C_{0} \rightarrow C$ is an initiation.

3. $\Pi$ : predicate diagram predetermined on $M$.

The category of $C$ specification is most often predetermined by the graph and by the set of decisions which is determined from predicate diagrams coincidence.

Let $C$ - to be a discrete category with two objects $(\mathrm{C}=$ $\{$ COLECTOR, DEPOSIT $\}$ ).

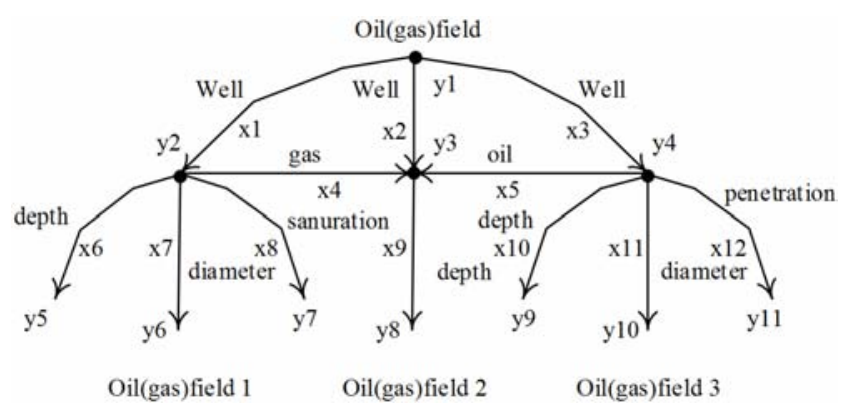

Figure 1. The information graph for oil-and-gas bearing deposits prediction.

DEPOSIT - is one or several pay horizons or areas, with common characteristics and common geological conditions, which are designed by the same well stock.

COLECTOR - is a reservoir for oil, gas or water, which has certain filtration capacitive characteristics that potentially allow holding or carrying the output.

This specification states that the object domain we want to formalize consists of two kinds of entity. Arrows in the category determine existent relations. For example:

$$
\eta=\underset{\begin{array}{c}
\text { COLECTOR } \\
\downarrow \\
\text { DEPOSIT }
\end{array}}{l_{l}} \cdot \mathrm{M}=0
$$

As the arrow is a function in the model, so there is a certain DEPOSIT for every COLECTOR.

The source with $n$ arrows in the category can be presented as $n$-ary multirelation:

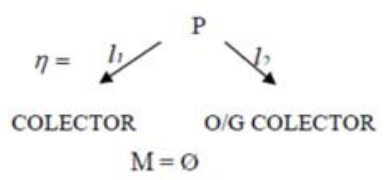

This specification shows that $\mathrm{P}=$ ffield and industrial geophysical evidence and core analysis $\}$ PARAMETERS is a multirelation between COLECTOR and O/G COLECTOR: for every object of PARAMETERS type is certain twain $(x$, $y$ ), where $x$ is of COLECTOR type, $y-\mathrm{O} / \mathrm{G}$ COLECTOR. The variant when different objects of PARAMETERS type fit with the equal twain. For example O/G COLECTOR can be determined by a various set of parameters.

Let's consider a prime multirelation (without reiterations):

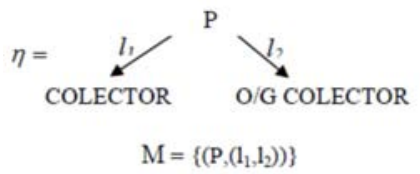

Here we can see that COLECTOR and O/G COLECTOR (oil and gas collector) are connected because of the same sets of PARAMETERS only. When $l_{1}-$ are the characteristics of analysis of gravimetric, magnetometric, and seismometric prospecting and electrical exploration; $l_{2}-$ are the characteristics of well survey and geological investigations.

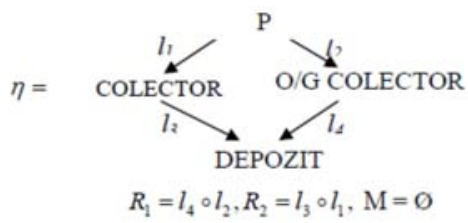

This specification shows that COLECTOR and $\mathrm{O} / \mathrm{G}$ COLECTOR can be determined by PARAMETERS, if they belong to the same deposit. Such kind of structural design is often used in practice. If we take previous affirmations as marks $l_{1}, l_{2}$, then $l_{3}-$ will be the characteristics of formation factor, void factor, the analysis of geographical location of inplace permeability; $l_{4}$ - void factor characteristics that are determined from core analysis, geophysical exploration, the analysis of geographical location. On the basis of affirmations given, the interpretation of composition $R_{l}$ and $R_{2}$ will acquire the following description:

$R_{1}$ - contingencies for characteristics of geological exploration analysis, for formation factor;

$R_{2}$ - contingencies for characteristics of void factor, for geophysical exploration analysis

In the previous examples functor $F$ was constant. Let it be:

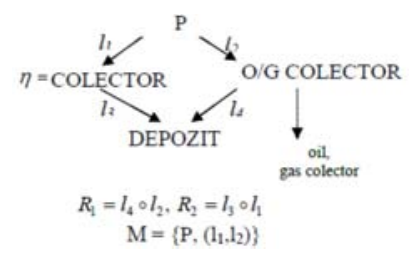

$F$ functor is represented in the figure by the dotted arrow. If there is a line from the graph junction to the finite set, so this is determined by the $F$ functor for the particular junction. Tat is $F(\mathrm{O} / \mathrm{G}$ COLECTOR $)$ is a set \{oil, gas, oil-and-gas collector $\}$. If there is no dotted line from $n$ junction, then $F(n)$ is an empty set. We can connect the $P$ set with the finite set of parameters, which characterize the COLECTOR, with the help of predefined $F$ functor. There exists [10] sufficiently large number of non-connected factors, which forecasts he collector at this level of scientific development, such as seismic prospecting, electrical exploration, gravimetrical prospecting, acoustic prospecting, core analysis, qualitative and quantitative composition of inherent carbohydrates. 
Let's consider a specification:

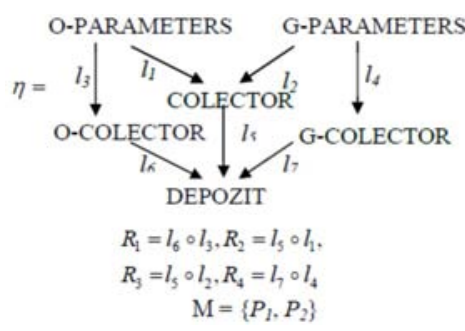

where $P_{1}=\{$ oil parameters $\}, P_{2}=\{$ gas parameters $\}$;

$l_{l}$ - the characteristics of saturation of formation, of geological structure, of formation factor;

$l_{2}$ - the characteristics of saturation of formation, of inplace permeability, of analysis of acoustic prospecting;

$l_{3}$ - the characteristics of reservoir oil saturation, of reservoir core analysis, of geological-geophysical prospecting;

$l_{4}$ - the characteristics of reservoir gas saturation, of geological exploration analysis, of reservoir thermobaric conditions analysis;

$l_{5}$ - the characteristics of geographical location analysis, of core analysis, of reservoir void factor;

$l_{6}$ - the characteristics of resource analysis, of reservoir void factor, of formation sample analysis on deposits, of electrical exploration analysis, of gas-oil factor;

$l_{7}$ - the characteristics of resource, reservoir porosity, acoustic drill hole survey and carbohydrates composition analysis.

On condition that the previous affirmations are true, compositions (contingencies) in the interpretation will obtain the following description:

$R_{I}$ - contingencies for characteristics of well survey analysis with the help of acoustic investigation, for core analysis;

$R_{2}$ - contingencies for characteristics of geological and geophysical parameters

$R_{3}$ - contingencies for characteristics of reservoir gas saturation and porosity factor;

$R_{4}$ - contingencies for characteristics of thermobaric conditions analysis, of gas ratio.

By the help of this specification we can provide the next example of dividing data of prognosticated field by objects. On this basis we will be able to prognosticate more precisely the geographic position, occurrence depth, power and structure of the field.

We have showed the set of data that we can call PARAMETERS. On their basis it can be defined if we have a collector or an oil and gas collector. Data of core analysis, gas saturation, thermo baric data and data of geological survey wells may be the parameters that characterize oil and gas collectors.

After having described the oil and gas deposit prognosticate possibility by the help of category theory, let us develop it. We will formalize the inorganic deposit formation process in a borehole while hydrocarbon extracting.

The exploiting gas and gas condensed fluid fields is followed by the emergence of brine water in well bore products, especially at the late working phases. And as a result there appear complications connected with the inorganic substance formation and deposit in a borehole that is developed, in pipes and industrial equipment. Salt accumulation causes the diminution in cross-cut, pipe and equipment clogging, bed properties collector diminution and as a result it causes the break in gas mining at almost all fields that are developed.

The analysis of existing approaches that clear up the problem of inorganic substance deposit formation in borehole enables to make a conclusion that such a problem really exists and they are trying to solve it but only concerning certain inorganic substances. As most of the fields on the Ukrainian territory are under late stages of stripping, the inorganic substance prognostication problem down the borehole acquires economic implications.

The new technologies implementation on the microprocessor system basis in field of oil and gas enables to change significantly the economic ecological approach to well exploitation on the late stripping stages.

While exploiting gas and gas condensate fields with appearance of brine mineralized water in $u$ well products, we face the complications concerning the formation and sediment of inorganic salts in boreholes. During this process brine waters may also compound with hydrocarbons. All these phenomena make the brine waters compositions so complicated, variable and undefined that it is very hard to determine any middle index of this composition. All the more there are no reliable and full analytic researches in this sphere.

The analysis of info streams affirms that the main reasons for salt deposits are the following factors:

- The contact of chemically incompatible waters (different horizon water compounding or compounding of brine waters and condensate water);

- The change in thermodynamic conditions (temperature and pressure);

- The change in hydrodynamic conditions (reduction in speed of gas fluid stream in lift pipes and industrial communications);

- The salt contents in following brine waters (the salt concentration).

Besides the process of salt deposit formations is affected by:

- electric field;

- organic compounds;

- emulsion character in borehole;

- the nature of equipment surface;

- chemical reagents, that are used for mining gas and gas condensed fluid (methanol, hydrochloric acid etc.)

The formalization problem of chemical composition conduction process in brine waters that are transported through the well bore under different thermodynamic circumstances is very important.

The implemented analysis states that physical and chemical aspects of salt crystallization in a borehole are 
studied enough. Though for being able to prognosticate the multi component inorganic solution crystallization let us first take a view of working out formal logical mathematical model opportunity for the control and operation of onecomponent salt crystallization in borehole.

To define main parameters, that influence essentially the formation and growth speed of crystals and the inorganic salt deposits down the borehole formation possibility, it's necessary to prognosticate the deposit formations. The solving of this problem would be more effective if the speed of deposits down the borehole formation will be measured. So it would be possible to plan the funds for prevention activities.

Taking into account all mentioned earlier and after being acquainted with the crystallization process influence factors [1]. Some of them can be defined in stationary operation mode:

- borehole coalface temperature, and its allocation down the well bore;

- exploitation column diameter;

- borehole depth;

- appropriate salt concentration;

- kinds of salt [4].

In this work it is investigated in general the mathematical model for prognostication the deposit formations in a borehole mining gas and gas condensed fluid [5].

Considering the conclusion there were made some regularities that characterize the inorganic crystal formation. The basis for these regularities was the free energy in compound excess consideration (the free Gibbs' energy was used). There showed up the following results: salt deposits appear on a column wall in a borehole coalface that coincides with practical data.

Let us make an inorganic substance process formation category interpretation on the predicate scheme basic, using the preceding definitions:

Definition 1:

1. $C$ - finite inorganic deposits category;

2. $M$ - finite object set in $C$;

3. $F: C_{0} \rightarrow$ FinSet - factor, where $C_{0}$ is a discrete category and its object set is a $C$ object set.

Definition 2:

The use of informational graph for an oil and gas saturated deposits prognostication interpretation and indexes of quantity and quality that characterize inorganic deposit formations in a borehole (See draft 2):

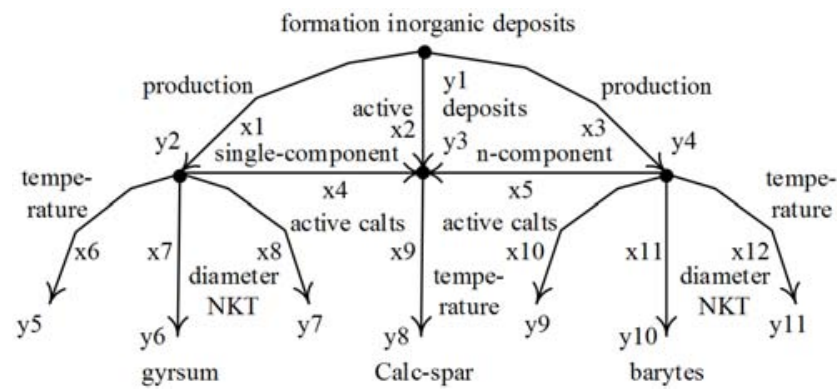

Figure 2. The directed graph information for interpreting the formation of inorganic substances in well bore at gas.

Draft 2: Directed informational graph for inorganic substance process formation interpretation in a borehole while hydrocarbon extracting.

Definition 3:

Let's consider that

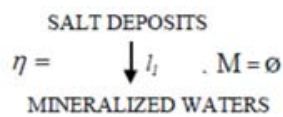

If $\mathrm{C}$ is a discrete category with two objects $(\mathrm{C}=$ \{ salt deposits, mineralized water $\}$ ). SALT DEPOSITS are hard formations in collector pores, on the pump-compressor pipe walls and in land equipment. MINERALIZED WATER is a high mineralized brine that contains a set of valuable components and can be considered as a hydro mineral raw material. As a result we can get a predicate interpretation diagram showed at the draft 2 .

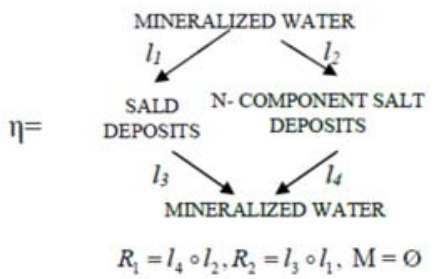

Here we can see that SALT DEPOSITS and $\mathrm{N}$ COMPONENT SALT DEPOSITS are connected only by the same set of parameters. $l_{l}$ are the thermo baric conditions characteristics; $l_{2}$ are the mineralizes water proof analysis characteristics.

This specification shows that SALT DEPOSITS and NCOMPONENT SALT DEPOSITS may be defined by the parameters if they belong to the same field. This kind of construction is often used practically. $l_{l}$ are the thermo baric conditions characteristics; $l_{2}$ are the mineralizes water proof analysis characteristics; $l_{3}$ are the temperature behavior analysis characteristics; $l_{4}$ are salt content concentration alteration dynamic analysis characteristics. On the basis of these statements the composition interpretation $R_{1}$ and $R_{2}$ will be the following: $R_{l}$ are the limitation for the characteristics for the component salt concentration.

Graph parameterization enables to formalize the inorganic substance deposit prognostication scheme while borehole stripping. We get the answer according to the given limitation by the categorical predicate diagram with the given graph matching method.

As there are problems with the intellectual system working out for the prognostication the inorganic deposit formations in a borehole while hydrocarbons mining, it is suggested to use the mechanism of dividing the index area and its description by the organizational models [15]. So, the received formalisms for the processes and objects of oil and gas index area description will be used for the description of roles and tasks of agents in an interaction and oil and gas index area object interplay intellectual multyagent result 
prognostication system working out.

\section{Conclusion}

In this research paper there was made a new approach to the oil and gas index area description at the category level and inorganic deposit in a borehole formation prognostication process at the category level. All this enables to represent the connections and differences between different informational streams that characterize the crystallization process in oil and gas index area conditions.

The suggested approach is the continuation of $[7-9,11,14$, 15] methods that had been suggested earlier. Their content is in a category theory use for the quantity and quality info streams calculation for the weak-structured oil and gas object description. It is efficient to use the existing oil and gas field stripping technologies on the basis of this theory.

The further research will be directed to:

- getting knowledge about oil and gas index area at the person request method development. This person makes decisions according to its informational needs;

- development of phased expert's knowledge formalization methods on the quantity and quality info stream basis, its structurization and work out while inorganic formations in a borehole crystallization process description;

- formal logic device enlargement.

\section{References}

[1] Yatsyshyn M. M., Dytko T. V., Bronovskyy I. V. Mathematical model of the crystallization of one-component salts in the trunk wells / / Exploration and development of oil fields 4 (17) 2005. - Ivano-Frankivsk. - pp. 42-45.

[2] F. Piessens, E. Steegmans "Categorical data-specification" Theory and Application of Categories, vol. 1, No. 8, 1995, pp. 156-173.

[3] Yurchyshyn V. M., Sheketa V. I. Classification attributes and relations in the formation of knowledge bases, oil and gas extraction facility / / Oil and gas industry-2001-№ 3 - P. 53 54.

[4] Sheketa V. I. "Information retrieval tasks based on restrictions for oil and gas domain" Journal of University of Technology / Engineering-2003. - № 3 (27)., P. 167-172.

[5] Handbook of petroleum affairs / Pod Society. yet. PhD V. S. Boyko, R. M. Kondrata, R. S. Yaremiychuka. - K.: Lviv, 1996. - P. 620.
[6] Yurchyshyn VM Using category theory to diagnose holes in their conservation and liquidation / / Scientific Bulletin of the National Technical University. - 2003. - № 1. - p. 121-124.

[7] M. Barr, C. Wells "Category Theory for Computing Science" Prentice Hall International Series in Computer Science, 1990.

[8] Mark Sims, Daniel Corkill, Victor Lesser, "Separating Domain and Coordination in Multi-Agent Organizational Design and Instantiation", Proceedings of the International Conference on Intelligent Agent Technology (IAT 2004), pp. 155-161. September 2004.

[9] Evolution of the GPGP/TAEMS Domain-Independent Coordination Framework / V. Lesser, K. Decker, T. Wagner, N. Carver, A. Garvey, B. Horling, D. Neiman, R. Podorozhny, M. Nagendra Prasad, A. Raja, R. Vincent, P. Xuan, and X. Zhang //.- Autonomous Agents and Multi-Agent Systems, July 2004.- 9 (1).- pp. 87-143.

[10] Yatsyshyn M. M. Intelligent system for prediction of inorganic deposits in the wellbore / M. M. Yatsyshyn / / Bulletin Khmelnitsky National University. Engineering - 2007. - № 6. Vol. 1 (100). - P. 156-160.

[11] Yatsyshyn M. M. Information categorical formalization of the process of formation of inorganic deposits in the wellbore at gas / MM Yatsyshyn / Eastern European Journal of advanced technologies. -2007. - № 6/5 (30). - P. 20-22.

[12] Yatsyshyn M. M. Formalizing the process of formation of inorganic deposits in the wellbore at gas / M. M. Yatsyshyn, M. B. Gorbal, V. M. Yurchyshyn / / Proceedings of X International Scientific and Technical Conference "System Analysis and Information Technologies", Kyiv, 20-24 May 2008.: Abstracts. - Kyiv: "KPI", 2008. - P. 170.

[13] Chesanovskyy M. The Formal Structuring of Subject Domain for oil and Gas Industry IT Applications / M. S. Chesanovskyy, V. I. Sheketa, V. M. Yurchyshyn, T. R. Styslo // Modern problems of radio engineering, telecommunications, and computer science (TCSET'2016): the XIII International Theoretical and Practical Conference, (Lviv-Slavske, 23-26 february, 2016). - Lviv, 2016. - P. 503 - 505.

[14] Gorbachuk, M. I Method and parallelization algorithms of synthesis of empirical models taking into account the measurement errors / Gorbachuk, M. I., Lazor, A. M., Pasyeka, M. S., Bandyra, V. V., Yurchak, I. Y. // Proceedings of 13th International Conference: The Experience of Designing and Application of CAD Systems in Microelectronics, CADSM 2015 - P. 319 -327.

[15] Sheketa V. The Construction of Technological Problems Cases for the Purpose of Intelligible Control / V. I. Sheketa, V. D. Melnyk, Y. L. Romanyshyn, M. S. Chesanovskyy // Perspective technologies and methods in MEMS design (MemsTech'2016) the XIIth International Conference, (LvivPolyana, 20-24 th April 2016). - Lviv, 2016. - P. 96 - 99. 